University of Nebraska - Lincoln

DigitalCommons@University of Nebraska - Lincoln

\title{
$9-2012$
}

\section{Is weak oral language associated with poor spelling in school-age children with specific language impairment, dyslexia or both?}

Jillian H. McCarthy

University of Tennessee Health Science Center, jmccar21@uthsc.edu

Tiffany Hogan

University of Nebraska - Lincoln, thogan2@unl.edu

Hugh W. Catts

University of Kansas, catts@ku.edu

Follow this and additional works at: https://digitalcommons.unl.edu/specedfacpub

Part of the Disability and Equity in Education Commons, and the Special Education and Teaching Commons

McCarthy, Jillian H.; Hogan, Tiffany; and Catts, Hugh W., "Is weak oral language associated with poor spelling in school-age children with specific language impairment, dyslexia or both?" (2012). Special Education and Communication Disorders Faculty Publications. 78.

https://digitalcommons.unl.edu/specedfacpub/78

This Article is brought to you for free and open access by the Department of Special Education and Communication Disorders at DigitalCommons@University of Nebraska - Lincoln. It has been accepted for inclusion in Special Education and Communication Disorders Faculty Publications by an authorized administrator of DigitalCommons@University of Nebraska - Lincoln. 


\title{
Is weak oral language associated with poor spelling in school-age children with specific language impairment, dyslexia or both?
}

\author{
Jillian H. McCarthy, ${ }^{1}$ Tiffany P. Hogan, ${ }^{2}$ and Hugh W. Catts ${ }^{3}$ \\ 1. Department of Audiology and Speech Pathology, \\ University of Tennessee Health Science Center, Knoxville, Tennessee \\ 2. Special Education and Communication Disorders, University of Nebraska-Lincoln, Lincoln, Nebraska \\ 3. Speech-Language-Hearing: Sciences and Disorders, University of Kansas, Lawrence, Kansas
}

Corresponding author - J. H. McCarthy, Department of Audiology and Speech Pathology, University of Tennessee Health Science Center, 527 South Stadium Hall, Knoxville, TN 37996, USA; email jmccar21@uthsc.edu

\begin{abstract}
The purpose of this study was to test the hypothesis that word reading accuracy, not oral language, is associated with spelling performance in school-age children. We compared fourth grade spelling accuracy in children with specific language impairment (SLI), dyslexia or both (SLI/dyslexia) to their typically developing grade-matched peers. Results of the study revealed that children with SLI performed similarly to their typically developing peers on a single-word spelling task. Alternatively, those with dyslexia and SLI/dyslexia evidenced poor spelling accuracy. Errors made by both those with dyslexia and SLI/dyslexia were characterized by numerous phonologic, orthographic and semantic errors. Cumulative results support the hypothesis that word reading accuracy, not oral language, is associated with spelling performance in typically developing school-age children and their peers with SLI and dyslexia. Findings are provided as further support for the notion that SLI and dyslexia are distinct, yet co-morbid, developmental disorders.
\end{abstract}

Keywords: spelling, language, dyslexia, specific language impairment

\section{Introduction}

Spelling is a complex process requiring knowledge of language-specific sound-to-letter mappings and letter patterns. For some, spelling is a laborious and difficult process whereas others spell words effortlessly. Individual differences in spelling skills have been linked to oral language and word reading abilities (Bishop \& Clarkson, 2003; Ricketts, Bishop, \& Nation, 2008; Swanson, Trainin, Necoechea, \& Hammill, 2003). According to connectionist models of word reading (Plaut, McClelland, Seidenberg, \& Patterson, 1996; Seidenberg \& McClelland, 1989; Strain, Patterson, \& Seidenberg, 1995) oral language influences spelling via semantic-orthographic connections, whereas word reading contributes to spelling via phonologic-orthographic connections. Previous spelling research on children with dyslexia and specific language impairment (SLI) has shown mixed results (Leonard, 1998; Lyon, Shaywitz, \& Shaywitz, 2003). 
Connectionist models of word reading (Plaut et al., 1996; Seidenberg \& McClelland, 1989; Strain et al., 1995) provide one way of examining how phonologic (spoken words), orthographic (printed words) and semantic (word meaning) representations interact and are modified for the purposes of spelling. These models suggest that during the early stages of literacy development children develop connections between phonologic and orthographic representations. However, as learning continues (i.e. children become better readers and spellers), there is less dependence on phonologic-orthographic connections, but more reliance on the semantic pathway between them. The semantic pathway is a direct link between the meaning of a word and its orthographic representation. This provides readers with a quicker and more efficient way to read and spell words, in particular words with less predictable or highly irregular letter to sound correspondences, such as "yacht" or "pint".

Two groups of children, those with dyslexia and those with SLI, are hypothesized to reveal how the connections used to spell words develop because each group has known deficits in one (or more) set of representations. Phonologic-orthographic connections provide information about letter-sound associations. For example, a review of the literature by Vellutino, Fletcher, Snowling, and Scanlon (2004) showed that children with dyslexia have difficulty encoding phonologic and orthographic information, therefore their word reading and spelling is impaired via deficient connections between phonologic and orthographic representations. In addition, the connection between semantic and orthographic representations offers a way to examine how vocabulary knowledge and the understanding of words, words parts and letters interface. Children with SLI exhibit deficient oral language, including semantic processing (Gray, 2004), which should lead to weak semantic-orthographic connections (Nation \& Snowling, 1998a). However, whereas a positive association between word reading and spelling is robust (Swanson et al., 2003; Zutell \& Rasinski, 1989), the link between oral language deficiencies and spelling is equivocal. Some studies show that children with SLI have poor spelling (Naucler, 2004), whereas others do not (Bishop, McDonald, Bird, \& Hayiou-Thomas, 2009; Mackie \& Dockrell, 2004). Four methodological issues may explain discrepant results.

First, SLI and dyslexia are highly co-morbid (Catts, Adlof, Hogan, \& Ellis Weismer, 2005). If word reading and spelling skills are associated more so than language and spelling skills, it follows that the extent to which a specific sample of children with SLI have co-morbid dyslexia (i.e. word reading problems) will explain the extent to which they have spelling difficulties. Simply stated, samples of children with SLI will show spelling difficulties if those children also have co-morbid dyslexia. On the other hand, children with SLI who have good word reading skills should show good spelling skills. Support for this hypothesis is found in a study of SLI in which those with normal word reading showed average spelling abilities. Bishop et al. (2009) examined the spelling abilities of 9- and 10-year-old children with SLI $(n=35)$, dyslexia $(n=73)$ or SLI and dyslexia $(n=54)$ compared to their typical peers $(n=176)$. Results revealed that their sample of children with SLI spelled as well as their typical peers, whereas the children with SLI and dyslexia showed poorer spelling than typical peers. Likewise, Larkin and Snowling (2008) found that those with language impairment and a concurrent reading disability exhibited poor spelling. A study of spelling including groups of children with SLI, dyslexia or both better isolates the link between word reading, oral language skills and spelling.

Examining spelling skills in dissociated groups also provides evidence on the debate about the relation between SLI and dyslexia. On one hand, models characterize children with SLI as having both semantic and phonologic processing deficits on a continuum from severe to mild (Bishop \& Snowling, 2004; see also Fraser, Goswami, \& Conti-Ramsden, 2010). According to this view, those with SLI and dyslexia have a phonological deficit, whereby those with an additional semantic deficit will have SLI and those without a semantic deficit will have dyslexia. However, recent studies (Bishop et al., 2009; Catts et al., 2005) have questioned this view by showing that some children 
with SLI have good word reading and phonological processing even though they have semantic deficits. Studies of spelling provide a deeper examination into the orthographic and phonologic skills of children with SLI and children with dyslexia because the written output can be examined in multiple ways. Whereas reading tasks may show that some individuals with SLI are able to accurately read words, spelling tasks have revealed phonologic and orthographic processing deficits in adults with compensated dyslexia (i.e. good word reading after intensive instruction/literacy experience; Bruck, 1993). Thus, it follows that an examination of spelling in children with SLI, dyslexia or both can be a window into phonologic and orthographic processing that can add to the debate on the role of phonological processing in SLI and dyslexia.

Second, spelling differences in those with SLI across studies may be the result of task differences. Mackie and Dockrell (2004) examined spelling accuracy in written narratives generated by children with SLI. Although the number of spelling errors was not statistically different from their age-matched peers, the authors noted that during narrative writing participants with SLI frequently commented that because they did not know how to spell a specific word they chose to use a word they could spell correctly. Similarly, Puranik, Lombardino, and Altmann (2007) examined spelling accuracy in written narratives with children with language impairment and dyslexia compared to their age-matched peers. Results suggested that children with language impairment and dyslexia were poorer spellers compared to their typical peers. In both of these cases, the sample from which spelling comparisons were made likely impacted the study's results. Analyzing written narratives may produce a biased sample of words for spelling analyses because those words were self-selected by the child. These self-selected words may include those words children spell more accurately than words they did not choose to spell. Noting this potential self-selection bias, many studies have examined the spelling skills of children with SLI or dyslexia using a spelling dictation task (Bishop \& Clarkson, 2003; Bishop et al., 2009; Bruck, 1993; Cassar, Treiman, Moats, Pollo, \& Kessler, 2005; Eisenmajer, Ross, \& Pratt, 2005; Moats, 1983; Naucler, 2004; Zourou, Ecalle, Magnan, \& Sanchez, 2010). A spelling dictation task including words varying in difficulty (e.g. consistent $v$ s. less consistent spelling patterns) may better reveal true spelling differences, if present. Such a task would allow for the inspection of spelling error patterns that may reveal further connections between orthography, phonology and semantics.

Third, spelling tasks yield written words that can be coded on a continuum coarsely as correct or incorrect or fine-grained by error type. For example, Naucler (2004) showed that children with SLI spelled the same number of words correctly compared to their age-matched peers in a singleword spelling task. However, error analyses revealed that misspelled words by children with SLI contained significantly more omissions. Coarse coding led to the conclusion that children with SLI had spelling skills in line with their typical peers, whereas fine-grained coding leads to the conclusion that their spellings were less mature than those of their typical peers whose errors contained mostly substitutions. Several studies examining the spelling differences in children with dyslexia have used coarse and fine-grained coding systems (Cassar et al., 2005; Moats, 1983). For example, Caravolas and Volin (2001) used both a coarse and a fine-grained coding system to examine the phonological spelling differences in children with dyslexia compared to their age-matched and spelling-age matched peers who spoke Czech. Coarse coding found the children with dyslexia did not differ from their spelling-age matched peers, but they scored significantly poorer than agematched peers. Fine-grained measures revealed no phonological spelling difference between children with dyslexia compared to their spelling-matched younger peers; however, children with dyslexia made significantly more phonological errors than their age-matched peers. Unlike studies of SLI, this study highlights the consistent finding that those with dyslexia have poor spelling revealed by both coarse and fine-grained coding systems. Clearly, a study of spelling reveals more information about individual differences in orthographic, phonologic, and semantic processing by including both coarse and fine-grained coding. 
A final methodological issue that leads to equivocal results across studies involves the level of independent variable - continuous or dichotomous - included in spelling analyses. Studies involving children with SLI have used group comparisons to determine spelling performance in relation to typical peers. Groups are selected based on predetermined criteria, for example, a standard score less than 85 on a language assessment. However, it is widely accepted that children with SLI are characterized by a range of language abilities from mild to severe. If a specific sample of children with SLI contains many with mild impairments it could be that their spelling is also less severe and as such may appear to be in line with age-matched peers who also have language abilities on a continuum. The reverse is also plausible. Each scenario would lead to different conclusions: either children with SLI have typical spelling abilities or they are poor spellers. Both types of analyses - group differences and individual variations - would provide a deeper appreciation of the link between oral language, word reading, and spelling.

In this study, we examine spelling abilities in children with SLI, dyslexia or both compared to their grade-matched typically developing peers. We hypothesized that word reading, not oral language skills, would be associated with spelling abilities in these groups. As such, we predicted that those with SLI who have weaker language skills would spell like their typically developing peers, whereas those with dyslexia, regardless of language abilities, would spell more poorly than their typically developing peers and those with SLI. Building on past studies, we consider co-morbidity by selecting discrete groups using a double dissociation of word reading and oral language: SLI, dyslexia, SLI/dyslexia and typically developing peers. Using double dissociation requires matching one pair of groups according to good language (typical peers and dyslexia) and another pair according to good word reading (typical peers and SLI). Further, one pair of groups matches on poor language (SLI and SLI/dyslexia) and another pair matches on poor word reading (dyslexia and SLI/dyslexia). Our task avoided selective spelling by requiring each child to spell individual words that contained both consistent and less consistent letter-to-sound mappings. Spellings were coded coarsely as correct or incorrect followed by fine-grained coding of errors. Analyses were conducted at two levels to capture individual variations within and across groups: (a) using participant groups and (b) using word reading and oral language to predict spelling. Specifically, we asked three research questions: First, do children with word reading problems (i.e. dyslexia and SLI/dyslexia) show spelling weaknesses compared to their peers with good word reading (i.e. SLI and typical peers)? Second, do individual differences in word reading predict spelling more so than oral language in children with variable word reading and oral language abilities? Third, do children with word reading problems (i.e. dyslexia and SLI/dyslexia) show a similar pattern of spelling errors, compared to their peers with good word reading (i.e. SLI and typical peers)?

\section{Methods}

\section{Participants}

Participants in this study were selected from a subsample of 604 children enrolled in a longitudinal investigation of language impairments in which oral language and reading measures were administered in kindergarten, second, fourth, eighth and tenth grades. These children had originally taken part in a large epidemiologic study of language impairments in over 7000 kindergarten children (Tomblin et al., 1997). This original sample of 7000+ was stratified by residential setting (i.e. rural, urban, suburban) and cluster sampled by school building. The sample was $33 \%$ rural, 37\% urban, 30\% suburban; 51\% male, 49\% female; and 83\% White, 12.7\% African American and $4 \%$ other (Tomblin et al., 1997; Tomblin, Records, \& Zhang, 1996). Due to attrition, 570 participants completed a spelling assessment in fourth grade. Of those children, three subgroups were selected to represent double dissociation in language and word reading following the methods of Catts et 
al. (2005): SLI $(n=43)$, dyslexia $(n=21)$ or both SLI and dyslexia $(n=18)$. In addition, a subset of grade-matched typically developing peers was selected $(n=47)$. In fact, participants were those included in the Catts et al. study with one exception: spelling data were examined in a random subset of approximately half of the grade-matched typically developing peers who were included in the Catts et al. study. This approach was taken so that the subgroups would contain a similar number of participants and so that spelling error coding, which is labor-intensive, would be reduced.

Participants with SLI showed marked impairments in language abilities with normal nonverbal intelligence. The criteria for SLI were based on kindergarten language composite and nonverbal intelligence scores (Tomblin et al., 1996). The decision to use kindergarten scores to identify SLI was made for two reasons. First, SLI is characterized by problems in the development of oral language and as such is often diagnosed during the preschool years (Leonard, 1998; Rice \& Wexler, 1996). Second, by identifying oral language impairments in kindergarten, prior to formal reading and spelling instruction, one reduces the impact of poor reading on language (Catts et al., 2005; Magnusson \& Naucler, 1990).

Dyslexia was diagnosed based on fourth grade measures of word reading and Full-Scale IQ using a regression-based Full-Scale IQ-word reading discrepancy model and low-achievement criterion. Fourth grade word reading abilities were used for participant selection because they represented the intermediate point in reading achievement in the longitudinal sample (Catts et al., 2005). An IQ-achievement discrepancy approach with a low-achievement criterion was used to ensure that participants with dyslexia showed low word reading abilities in spite of typical intelligence. This definition is in line with other research studies (Fletcher et al., 1994; McArthur, Hogben, Edwards, Heath, \& Mengler, 2000; Meyer, Wood, Hart, \& Felton, 1998; Pennington, Gilger, Olson, \& DeFries, 1992; Shaywitz, Shaywitz, Fletcher, \& Escobar, 1990; Snowling, Bishop, \& Stothard, 2000; Snowling, Gallagher, \& Frith, 2003) and recent definitions of dyslexia (Lyon et al., 2003). For this study, the regression-based method used a proxy for Full-Scale IQ to predict word reading scores (Catts et al., 2005; Snowling et al., 2000). Specifically, Full-Scale IQ was not assessed in fourth grade as part of the longitudinal study. Therefore, children's scores from their nonverbal IQ measure in second grade were combined with verbal intelligence scores from fourth grade to create an estimate of Full-Scale IQ. Participants were identified as having dyslexia if their fourth grade word reading was more than 1 SD below their predicted word reading score based on their Full-Scale IQ (Catts et al., 2005). Normal word reading was defined as word reading abilities in line with Full-Scale IQ in fourth grade. Word reading was a composite measure of real word and nonword reading skills (Woodcock, 1987).

Based on these diagnoses, three subgroups were formed. The first subgroup consisted of participants diagnosed with SLI in kindergarten and normal word reading in fourth grade, henceforth labeled participants with SLI. The second subgroup, labeled participants with dyslexia, consisted of participants with a dyslexia diagnosis in fourth grade but no SLI diagnosis in kindergarten. The third subgroup, labeled participants with SLI/dyslexia, was composed of participants who had an SLI diagnosis in kindergarten and a dyslexia diagnosis in fourth grade. The final subgroup, labeled typically developing grade-matched peers (typical peers), included participants who did not have an SLI diagnosis in kindergarten and showed normal word reading in fourth grade.

The language and word reading scores, as well as nonverbal and Full-Scale IQ scores for each subgroup are displayed in Table I. Analyses of variance (ANOVA) confirmed subgroup differences in language, $F(3,125)=61.98, p<0.001$, and in word reading, $F(3,125)=160.61, p<0.001$. Tukey's honestly significant difference test for unequal Ns revealed that participants with SLI and SLI/dyslexia had significantly lower language scores (SLI $M=77.57$, SD $=6.45$; SLI/dyslexia $M=76.88$, $\mathrm{SD}=5.88$ ) than the participants in the dyslexic and typical peer subgroups (dyslexia $M=90.84$, $\mathrm{SD}=8.12$; typical peers $M=105.67, \mathrm{SD}=15.22 ; p<0.001, d \mathrm{~s}=1.912-2.393$ ). These differences were expected on the basis of subgroup selection criteria. Further, participants with SLI and SLI/dys- 
lexia did not differ significantly in language composite scores $(p=0.996, d=0.112)$. However, the dyslexia subgroup participants did have a significantly lower mean language score compared to the typical peer subgroup participants $(p<0.001, d=1.12)$. When examining word reading, the SLI and typical peer subgroups did not differ significantly (SLI $M=105.36$, SD $=6.4$; typical peer $M=109.33, \mathrm{SD}=9.54 ; p=0.133, d=0.489)$; however, the SLI/ dyslexia subgroup participants scored significantly lower than the dyslexia subgroup participants (SLI/dyslexia $M=67.68, \mathrm{SD}=12.13$; dyslexia $M=75.14, \mathrm{SD}=6.42 ; p<0.001, d=0.805$ ).

All participants were native English speakers and each resided in homes in which English was the primary language. No participant had a concomitant diagnosis, such as Down syndrome or autism, upon enrollment of the longitudinal study in kindergarten. In terms of demographics, the longitudinal sample, and by extension the random subsample, is representative of the region in which the sample was conducted (i.e. state of Iowa - midwest portion of the USA).

\section{Procedures}

Testing was conducted by trained examiners with undergraduate or graduate degrees in speech-language sciences/pathology or education. All testing took place in a quiet classroom or mobile data collection unit. Measures used in this study were included in a battery of assessments administered during two, 2-h sessions during kindergarten, second and fourth grades.

\section{Materials}

Measures of oral language, intelligence and word reading were used to identify children with SLI and dyslexia. Additionally a standardized test of spelling was administered in fourth grade.

Language - Language abilities were assessed in kindergarten using the Test of Language Development-Primary: 2 (TOLD-P:2; Newcomer \& Hammill, 1988) and a narrative story task (Culatta, Page, \& Ellis, 1983). The narrative story task, particularly the narrative production subtest, quantifies oral language abilities. From these measures, five composite z-scores were created. Z-scores were based on the weighted means and standard deviations of the local normative sample of 1502 children who received the entire test battery in kindergarten as part of the original epidemiologic study (Tomblin et al., 1996, 1997). The scores from Picture Identification and Oral Vocabulary subtests of the TOLD-P:2 were combined to form a vocabulary composite score. The subtests of Grammatic Understanding, Grammatic Completion and Sentence Imitation from the TOLD-P:2 were

Table I. Language, word reading, nonverbal intelligence and full-scale intelligence by subgroup.

\begin{tabular}{|c|c|c|c|c|c|c|c|c|}
\hline & \multicolumn{2}{|c|}{$\begin{array}{r}\text { Participants } \\
\text { with } \\
\text { SLI only } \\
(n=43)\end{array}$} & \multicolumn{2}{|c|}{$\begin{array}{r}\text { Participants } \\
\text { with } \\
\text { dyslexia } \\
(n=21)\end{array}$} & \multicolumn{2}{|c|}{$\begin{array}{r}\text { Participants } \\
\text { with } \\
\text { SLI/ dyslexia } \\
(n=18) \\
\end{array}$} & \multicolumn{2}{|c|}{$\begin{array}{r}\text { Typically } \\
\text { developing } \\
\text { grade-matched } \\
\text { peers }(n=47)\end{array}$} \\
\hline & $M$ & SD & $M$ & $\mathrm{SD}$ & $M$ & SD & $M$ & SD \\
\hline Language (K) & $77.6^{\mathrm{a}}$ & 6.5 & $90.8^{b}$ & 8.1 & $76.9^{a}$ & 5.9 & $105.7^{c}$ & 15.2 \\
\hline Word reading (fourth grade) & $105.4^{\mathrm{a}}$ & 6.4 & $75.1^{b}$ & 6.4 & $67.7^{\mathrm{b}}$ & 12.1 & $109.3^{\mathrm{a}}$ & 9.5 \\
\hline Nonverbal IQ (K) & $101.6^{\mathrm{a}}$ & 9.2 & $103.9^{\mathrm{a}}$ & 12.4 & $99.4^{\mathrm{a}}$ & 8.9 & $104.9^{\mathrm{a}}$ & 11.7 \\
\hline Full-scale IQ (fourth grade) & $90.5^{\mathrm{a}}$ & 10.8 & $99.0^{\mathrm{b}, \mathrm{c}}$ & 9.3 & $92.1^{\mathrm{a}, \mathrm{b}}$ & 10.0 & $106.2^{c}$ & 11.1 \\
\hline
\end{tabular}

Means in the same row that do not share superscripts differ at $p<0.05$ in Tukey's honestly significant difference test for unequal Ns; $\mathrm{K}=$ kindergarten. 
used to form the grammar composite score. Scores from the Narrative Comprehension and Narrative Recall subtests were employed to create the narrative comprehension composite score. A receptive language composite score was calculated using the z-scores from the Picture Identification, Grammatic Understanding and Narrative Comprehension subtests. An oral expressive language composite score was derived by combining the z-scores of the Oral Vocabulary, Grammatic Completion, Sentence Imitation and Narrative Recall tasks. An overall language composite score was also calculated using the expressive and receptive language composite scores. Participants who scored 1.25 SD below the mean on 2 or more composites were diagnosed with language impairment. Those with nonverbal intelligence $>1$ SD were diagnosed with SLI as outlined above (see Tomblin et al., 1996, 1997 for full summary of kindergarten SLI diagnostic criteria).

Language abilities were assessed again in fourth grade using the Clinical Evaluation of Language Fundamentals - 3 (Semel, Wiig, \& Secord, 1995), the Peabody Picture Vocabulary Test-Revised (PPVT-R; Dunn \& Dunn, 1981) and the Comprehensive Receptive and Expressive Vocabulary Test (Wallace \& Hammill, 1994). Combining the z-scores of each of the measures derived an overall language composite score. Z-scores were based on the weighted means and standard deviations of the local normative sample of 570 children who were part of the full epidemiologic study at fourth grade (Tomblin et al., 1996, 1997).

Intelligence - Estimates of both nonverbal and Full-Scale IQ were used as criteria when diagnosing SLI and dyslexia. Verbal intelligence was estimated in fourth grade using the PPVT-R (Dunn \& Dunn, 1981). Nonverbal intelligence was not reassessed in fourth grade. However, in second grade, nonverbal intelligence was assessed using the full Performance Scale of the Wechsler Intelligence Scale for Children-III (Wechsler, 1991). To obtain an estimate of full-scale intelligence in fourth grade, scores on the PPVT-R were combined with those on the second grade nonverbal intelligence measure to form a composite z-score based on weighted means and standard deviations of the original 604 children enrolled in the longitudinal investigation.

Word reading - The Word Identification and Word Attack subtests of the Woodcock Reading Mastery Test-Revised (Woodcock, 1987) were administered in fourth grade. The Word Identification subtest assessed participants' ability to correctly pronounce printed English words ranging from high to low frequency. The Word Attack subtest measured participants' ability to read pronounceable nonwords varying in complexity. Because word reading skills rely heavily on instruction, standardized scores were assigned using grade-based assessment norms from the test manual. Further, a composite z-score for word reading was formed by transforming the standard scores from the two subtests into a z-score.

Spelling - The Test of written spelling - Third Edition (TWS-3; Larsen \& Hammill, 1994) consists of 100 written words. Participants were required to write target words given to them orally in isolation (e.g. stop) and in a simple sentence (e.g. stop talking now). The TWS-3 was discontinued when a participant incorrectly spelled 10 words in a row. The raw score was the total number of words spelled correctly. It is important to note that the raw scores for the total correct were analyzed in this study. Though the TWS-3 does provide standard scores, these scores are based on the age of the child, thus the influence of previous spelling instruction is not considered (see Hammill \& Bartel, 1990).

In addition to calculating number correct, spelling errors were coded to determine if qualitative spelling differences were evident between groups. A multiple-linguistic approach coding system (Apel \& Masterson, 2001; Masterson \& Apel, 2010) was used to identify phonological awareness (PA) errors, orthographic pattern awareness (OPA) errors, mental graphemic representations (MGR), morphological awareness (MA) errors and semantic awareness (SA). A multiple-linguis- 
tic approach to examining spelling errors focuses on determining which factor or factors are leading to spelling difficulties (Apel \& Masterson, 2001; Masterson \& Apel, 2010). PA is one's ability to think about, talk about and manipulate speech sounds (Table II). OPA is the ability to translate language from spoken to written form, specifically focusing on spelling patterns and conventions. MGR errors were those involving an incorrect mental picture of a written word. MA is one's ability to consider morphemes, their spelling and the semantic connections between a root word and its corresponding inflectional and derivational forms. Unfortunately, there are few words on TWS-3 that contain derivational morphology. Moreover, words containing morphological endings were mostly contained toward the end of the test which limited those with spelling difficulty who met the test's ceiling early; providing children who had spelling difficulties with fewer opportunities to spell these words compared to good spellers. Therefore, errors were not coded for MA, a limitation of this study. Finally, SA is one's ability to think about the effect of spelling on word meanings.

Scoring reliability was calculated to ensure accuracy of error coding (i.e. PA, OPA, MGR, MA, SA) across both words and participants. Additionally, scoring reliability was calculated to ensure that the coded errors were correctly summed across error codes across participants. The first author trained a speech-language pathology undergraduate student to code spelling errors prior to completing scoring reliability. Reliability calculations were obtained by comparing the first author's coding and summations with the undergraduate student's coding and summations completed across $20 \%$ of the words and $20 \%$ of the participants. Inter-judge scoring reliability for words was $99.68 \%$ and $99.11 \%$ across participants.

\section{Results}

The first research question we addressed was: Do children with word reading problems (i.e. dyslexia only and SLI/dyslexia) show spelling weaknesses compared to their peers with good word reading (i.e. SLI only and typical peers)? The number of correctly spelled words was analyzed using a mixed ANOVA with one between subjects factor, subgroup (SLI vs. dyslexia vs. SLI/dyslexia vs. typical peers). Results indicated that there was a significant main effect of group, $F(3,125)=43.14, p<0.01, \eta_{p}^{2}=0.51$. Thus, children with word reading problems showed a weakness in spelling compared to children with good word reading, regardless of language abilities.

Table II. Multiple-linguistic error codes for spelling.

\begin{tabular}{|c|c|}
\hline Error type & Description \\
\hline $\begin{array}{l}\text { Phonological } \\
\text { awareness }\end{array}$ & $\begin{array}{l}\text { Spellings with either a sound added or omitted (e.g. hm for him; etire for entire; top for stop) } \\
\text { Words with letter reversals (e.g. sotp for stop; flod for fold) that change the sound order }\end{array}$ \\
\hline $\begin{array}{l}\text { Orthographic pattern } \\
\text { awareness }\end{array}$ & $\begin{array}{l}\text { Spellings with incorrect sound-symbol correspondences (e.g. beb for bed) } \\
\text { Incorrect rules for combining letters (e.g. whent for went) } \\
\text { Incorrect patterns that govern spelling within the root or base word (e.g. lader for ladder) } \\
\text { Incorrect positional constraints on spelling patterns (e.g. neckst for next) }\end{array}$ \\
\hline $\begin{array}{l}\text { Mental graphemic } \\
\text { representation }\end{array}$ & $\begin{array}{l}\text { Spellings with a phonetic spelling of a non-phonetic word (e.g. shace for shake) } \\
\text { Incorrect spelling of unstressed syllables and vowels preceding } n g, r, l \text { (e.g. buckit for bucket) } \\
\text { Any example of where one "just needs to now it is spelled that way" (e.g. abel for able) }\end{array}$ \\
\hline $\begin{array}{c}\text { Morphological } \\
\text { awareness }\end{array}$ & $\begin{array}{l}\text { Spellings with deleted morphological units (e.g. jump for jumped) } \\
\text { Incorrect or deleted spelling of affixes (e.g. brandsh for brandish) } \\
\text { Incorrect or deleted suffix modification rules (e.g. joging for jogging) }\end{array}$ \\
\hline Semantic awareness & $\begin{array}{l}\text { Correct spellings that indicate the wrong meaning of the words was used (e.g. one for won; to } \\
\text { for two; ate for eight) }\end{array}$ \\
\hline
\end{tabular}

Adapted from Apel and Masterson (2001) and Masterson and Apel (2010). 




Figure 1. Total correct raw score on the TWS-3 by subgroup. Error bars represent standard error of the mean.

Tukey's honestly significant difference test for unequal Ns (Tukey, 1953) was used to examine subgroup pairwise comparisons. Total correct from the TWS-3 is displayed in Figure 1 per subgroup. Analyses showed that participants in the SLI subgroup $(M=26.14, \mathrm{SD}=7.13)$ did not differ from their typical peers $(M=28.79, \mathrm{SD}=8.82)$ on spelling accuracy $(p=0.09, d=0.33$, respectively). Children in the dyslexia subgroup $(M=13.33, \mathrm{SD}=4.49)$ and children in the SLI/dyslexia subgroup $(M=10.39, \mathrm{SD}=5.25)$ did not differ in spelling accuracy $(p=0.21, d=0.62)$; however, both subgroups differed significantly from the typically developing peers and those with SLI $(p<0.001$, $d \mathrm{~s}=2.02-2.41$ ).

The second research question we examined was: Do individual differences in word reading predict spelling more so than oral language in children with variable word reading and oral language abilities? To take advantage of the full range of oral language and reading scores to verify the findings from research question 1, regression analyses were completed. We predicted that word reading skills would have a stronger association with spelling than oral language.

Regression analyses were used to determine the amount of unique variance (part correlation; denoted by sr) predicted by concurrent (i.e. fourth grade) oral language and word reading abilities on spelling of target words (i.e. total raw score of the TWS-3). Table III contains the results of these regressions. Results show that word reading $(\mathrm{sr}=0.803, p<0.001)$ was a significant predictor of overall spelling ability whereas oral language was not a significant predictor of overall spelling ability ( $\mathrm{sr}=0.039, p=0.360)$.

The third research question we addressed was: Do children with word reading problems (i.e. dyslexia only and SLI/dyslexia) show a similar pattern of spelling errors, compared to their peers with good word reading (i.e. SLI only and typical peers)?

Recall that a multiple-linguistic approach coding system was used to identify PA errors, OPA errors, MGR and SA (Apel \& Masterson, 2001; Masterson \& Apel, 2010) on misspelled words. Percent error type served as the dependent variable. Percentage was used because participants did not have the same number of opportunities to spell words due to the TWS-3 ceiling rule (i.e. children in the dyslexia and SLI/dyslexia subgroups had fewer opportunities to spell words). 
Scores were analyzed using a mixed ANOVA with one between subjects factor, Subgroup (SLI vs. dyslexia vs. SLI/dyslexia vs. typical peers) and one repeated measure, Error Type (PA vs. OPA vs. MGR vs. SA). Results indicated that there were two significant main effects, Subgroup, $F(3$, $125)=39.50, p<0.001, \eta_{p}^{2}=0.49$, and Error Type, $F(1,125)=58,83 p<0.001, \eta_{p}^{2}=0.32$. To decompose the significant two-way interaction between Error Type and Subgroup, separate ANOVAs were employed for each Error Type.

\section{Phonologic errors}

Using only data from the PA errors, a mixed ANOVA containing one between groups factor, Subgroup (SLI vs. dyslexia vs. SLI/dyslexia vs. typical peers) and one within group factor, Error Type (PA) was employed (Figure 2). The analysis of PA errors indicated a significant main effect of Subgroup, $F(3,125)=24.61 p<0.001, \eta_{p}^{2}=0.37$, Tukey's honestly significant difference test for unequal Ns (Tukey, 1953) was used to determine significant pairwise subgroups comparisons. Children with SLI $(M=0.08, \mathrm{SD}=0.05)$ and their typical peer group $(M=0.06, \mathrm{SD}=0.05)$ made fewer PA errors $(p=0.23, d=0.37)$ than children with dyslexia $(M=0.17, \mathrm{SD}=0.07)$ and SLI/dyslexia $(M=0.21, \mathrm{SD}=0.15)$ subgroups $(p=0.10, d=0.36)$, who made a similar number of PA errors $(p=0.10, d=0.36)$.

\section{Orthographic pattern errors}

Analysis of OPA errors revealed a main effect of Subgroup, $F(3,125)=40.26, p<0.001, \eta_{p}^{2}=0.49$. Children in the SLI/dyslexia $(M=0.33, \mathrm{SD}=0.09)$ and dyslexia subgroups $(M=0.32, \mathrm{SD}=0.09$; $p=0.62, d=0.12)$ exhibited more OPA errors than children in the SLI $(M=0.19$, SD $=0.06)$ and typical peer subgroups $(M=0.16, \mathrm{SD}=0.06 ; p=0.03, d=0.58)$. However, children in the SLI subgroup made significantly more OPA errors than the typical peer subgroup $(p=0.03, d=0.59)$.

\section{MGR errors}

Analysis of MGR errors revealed a main effect of Subgroup, $F(3,125)=15.91, p<0.001, \eta_{p}^{2}=0.28$. Children in the SLI $(M=0.11, \mathrm{SD}=0.05)$ and typical peers subgroups $(M=0.14, \mathrm{SD}=0.06 ; p=0.01$, $d=0.57)$ exhibited more MGR errors than children in the dyslexia $(M=0.06, \mathrm{SD}=0.04)$ and SLI/ dyslexia subgroups $(M=0.07, \mathrm{SD}=0.05 ; p=0.60, d=0.20)$. Children in the dyslexia and SLI/dyslexia subgroups were not significantly different in their MGR errors $(p=0.60, d=0.20)$.

\section{Semantic errors}

Analysis of SA errors revealed a main effect of Subgroup, $F(3,125)=30.75, p<0.001, \eta_{p}^{2}=0.43$. Children in the SLI/dyslexia $(M=0.09, \mathrm{SD}=0.06)$ and dyslexia subgroups $(M=0.07, \mathrm{SD}=0.04$; $p=0.10, d=0.35)$ exhibited more SA errors than children in the SLI $(M=0.02, \mathrm{SD}=0.02)$ and typical peer subgroups $(M=0.02, \mathrm{SD}=0.02 ; p=0.69, d=0.13)$.

Table III. Summary of hierarchical regression analysis for word reading and language skills when predicting spelling abilities of overall spelling accuracy $(N=129)$.

\begin{tabular}{lllllllll}
\hline & Variable & $B$ & SE B & $\beta$ & $R^{2}$ & Partial & Part sr & $p$ \\
\hline Total correct & $\begin{array}{l}\text { Kindergarten language } \\
\text { comprehension standard score } \\
\text { Word reading in fourth grade } \\
\text { standard score }\end{array}$ & 0.043 & 0.047 & 0.042 & 0.350 & 0.082 & 0.039 & 0.360 \\
& 0.777 & 0.041 & 0.860 & 0.876 & 0.858 & 0.803 & 0.000 \\
\hline
\end{tabular}




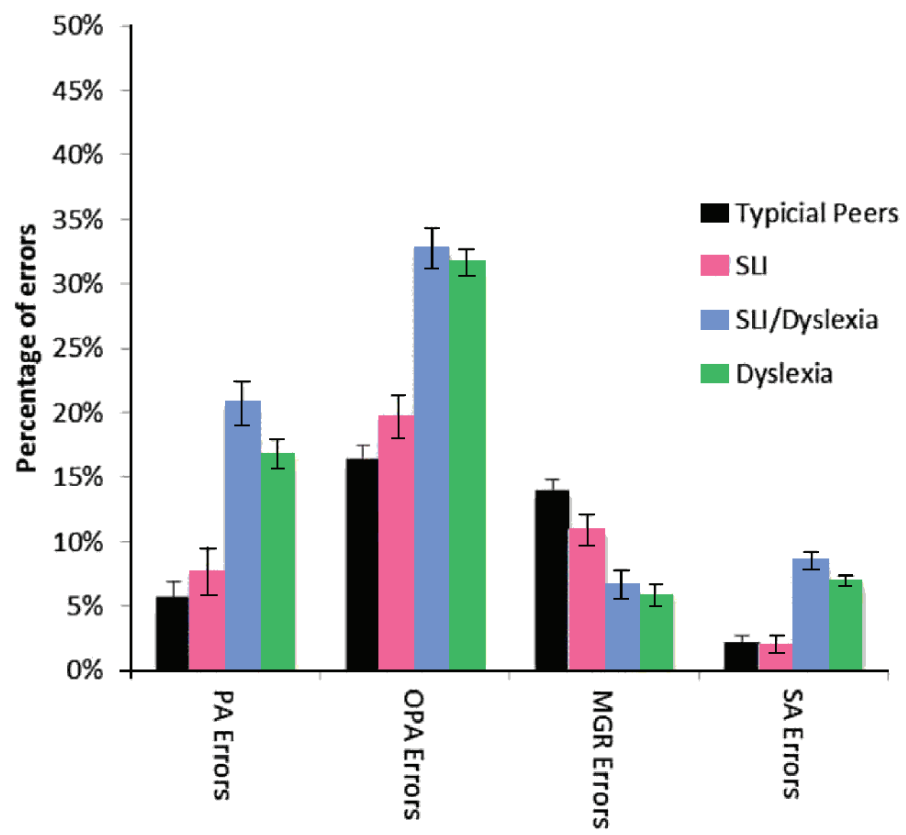

Figure 2. Mean number of errors on words on the TWS-3 made by subgroup. Error bars represent standard error of the mean.

\section{Discussion}

In this study, we examined how oral language and word reading related to spelling skills in children with SLI, dyslexia or both compared to their grade-matched typically developing peers. We predicted that word reading, not oral language, would be related to spelling. To test our hypothesis, we addressed four methodological issues we believe led to equivocal findings on the link between oral language and spelling in past studies.

First, we systematically examined the spelling of words from the TWS-3 to ensure that spelling was not limited to self-selected generation tasks (e.g. written narratives; Mackie \& Dockrell, 2004; Puranik et al., 2007) that limit the number of word types to be analyzed. Although we took a strong stance and predicted that oral language would not be related to spelling, it would not have been surprising to find that those with SLI, who by definition have semantic deficits, showed more spelling errors due to weaknesses via semantic-orthographic connections (Nation \& Snowling, 1998b). This was not the case: children with SLI spelled words at the same level of accuracy as their typical peers, except for two subtle differences (discussed below). These findings provide strong support for our hypothesis that oral language has limited influence on spelling. Word reading, specifically decoding of single words, on the other hand, was directly related to spelling accuracy.

The second issue we addressed was the high rate of co-morbidity between SLI and dyslexia. Because those with SLI are more likely to have poor word reading (i.e. dyslexia), past studies showing that children with SLI have poor spelling may have been confounded by not controlling for word reading differences. We addressed this issue by selecting discrete groups using a double dissociation of word reading and oral language: SLI, dyslexia, SLI/dyslexia and typical peers. Group analyses supported our hypothesis that oral language is not related to spelling once word reading abilities are controlled: children with dyslexia and those with SLI/dyslexia performed in a similar 
manner and scored significantly lower than their peers with intact word reading skills (i.e. SLI and typical peers) on our single-word spelling task. Those with SLI/dyslexia showed the poorest spelling performance among the subgroups. This was not surprising considering that children with SLI/ dyslexia had more severe word reading deficits compared to those with dyslexia alone. In post hoc analyses, when word reading skills were co-varied, the groups exhibited equally poor spelling accuracy when compared to children with SLI and their typical peers. Moreover, these results showcase the importance of the phonologic-orthographic connection in connectionist models of reading compared to the semantic-orthographic connection; a child's word reading abilities, or decoding of single words, are more important than his/her oral language for spelling single words.

A third methodological issue was related to the level of analyses used in past studies. In this study, we examined both group comparisons and individual differences to determine the extent to which oral language and word reading were related to spelling. Regression analyses that took advantage of the range of oral language and word reading abilities in our sample were in line with our group comparisons. Word reading was associated with correct spelling, while oral language was not (see also Swanson et al., 2003).

Finally, we argued that past studies of spelling often did not take advantage of the written output provided by spelling tasks. In particular, error analyses of spellings provide a thorough examination of the phonologic, orthographic and semantic skills of children. Our findings support this assertion; coding of errors revealed one subtle difference between those with SLI and their typical peers that was not evident by coarsely coding words as correct or incorrect. Children with SLI and no word reading deficiencies showed more orthographic-related errors compared to their typical peers. Even though these types of errors were more closely aligned to the errors made by their typical peers than their peers with dyslexia and SLI/dyslexia, this finding is in line with several previous studies showing that kindergarten children with language impairment have difficulty learning and remembering orthographic representations of words (Nation \& Snowling, 1998b; Wolter \& Apel, 2010), especially those words with irregular patterns that rely on semantic-orthographic connections (i.e. leap or yacht; Wolter \& Apel, 2010). On balance, analysis of errors supported our general hypothesis: children with word reading deficits, regardless of oral language, made similar types of spelling errors.

\section{Theoretical and Clinical Implications}

Our findings are in line with the view that SLI and dyslexia are co-morbid disorders (Bishop et al., 2009; Catts et al., 2005; Eisenmajer et al., 2005). The focus of this examination was to enhance our understanding of the spelling differences between SLI and dyslexia as a way to further examine the nature of this co-morbidity. Speech-language pathologists and educators should be aware that children with SLI, dyslexia and SLI/dyslexia will very likely struggle to read at an age-appropriate level, whether in word reading or reading comprehension. This examination is the first in understanding the specific types of errors made by each subgroup. Additional research is required to more fully understand how oral language and word reading influence spelling during the earlier grades, along with how to teach the spelling rules to children across the grades.

\section{Limitations and Future Directions}

This study took advantage of spelling, language and word reading data from a longitudinal database. First, the spelling data were collected using a standardized test; however, future studies should consider administering spelling measures with words that vary systematically in orthography, phonology and morphology. Second, future research should consider administering a spelling measure that does not employ a ceiling rule. For this study, children in the dyslexia and SLI/ 
dyslexia subgroups were noted to have fewer opportunities to spell words than the children in the SLI subgroup as well as their typical peers due to the ceiling requirement of the TWS-3. By administering measures without ceiling or basal rules, the number of spelling opportunities would be systematic across all subgroups. Finally, only the spelling data results from fourth grade are presented within this article. It would be informative to observe spelling performance in these subgroups in earlier and later grades to determine trajectories of learning. Observations of developing skills would allow a more direct examination of how oral language and word reading influences spelling skills over time.

\section{Conclusion}

In conclusion, our results are in line with the view that SLI and dyslexia are co-morbid disorders (Bishop et al., 2009; Catts et al., 2005; Eisenmajer et al., 2005). By analyzing written spellingboth accuracy and error analyses - we showed that those with dyslexia, regardless of oral language skills, had poor spelling indicative of deficient phonologic-orthographic connections. Further, although some past studies showed that children with SLI had spelling difficulties, we showed that only children with SLI who had poor word reading had poor spelling. Those with SLI who had typical word reading had typical spelling. As shown in this study, spelling provides a direct window into the influence of oral language and word reading on phonologic-orthographic and semantic-orthographic connections between words.

Acknowledgments - This study was supported by grants from the National Institute on Deafness and Other Communication Disorders (1-P50-DC2726-04; R03-DC9667; F31-DC010965-02). The authors wish to thank the following individuals: J. Bruce Tomblin, Xuyang Zhang, Paula Buckwalter, Marlea O'Brien, Connie Ferguson, Jodi Schwatz, Amy Kundel, Allie Krase, and Megan Schweitzer. We are particularly appreciative of the time and effort provided by the parents and children involved in this study.

\section{References}

Apel, K., \& Masterson, J. (2001). Theory-guided spelling assessment and intervention: A case study. Language, Speech, and Hearing Services in Schools, 32, 182-195.

Bishop, D. V. M., \& Clarkson, B. (2003). Written language as a window into residual language deficits: A study of children with persistent and residual speech and language impairments. Cortex, 39, 215-237.

Bishop, D. V. M., McDonald, D., Bird, S., \& Hayiou-Thomas, M. E. (2009). Children who read words accurately despite language impairment: Who are they and how do they do it? Child Development, 80, 593-605.

Bishop, D. V. M., \& Snowling, M. J. (2004). Developmental dyslexia and specific language impairment: Same or different? Psychological Bulletin, 130, 858-886.

Bruck, M. (1993). Component spelling skills of college students with childhood diagnoses of dyslexia. Learning Disability Quarterly, 16, 171-184.

Caravolas, M., \& Volin, J. (2001). Phonological spelling errors among dyslexic children learning a transparent orthography: The case of Czech. Dyslexia, 7, 229-245.

Cassar, M., Treiman, R., Moats, L., Pollo, T. C., \& Kessler, B. (2005). How do the spellings of children with dyslexia compare with those of nondyslexic children? Reading and Writing, 18, 27-49.

Catts, H. W., Adlof, S. M., Hogan, T. P., \& Ellis Weismer, S. (2005). Are specific language impairment and dyslexia distinct disorders? Journal of Speech, Language, and Hearing Research, 48, 1378-1396.

Culatta, B., Page, J., \& Ellis, J. (1983). Story retelling as a communicative performance screening tool. Language, Speech, and Hearing Services in Schools, 14, 66-74. 
Dunn, L. M., \& Dunn, L. M. (1981). Peabody picture vocabulary test-revised. Circle Pines, MN: American Guidance Service.

Eisenmajer, N., Ross, N., \& Pratt, C. (2005). Specificity and characteristics of learning disabilities. Journal of Child Psychology and Psychiatry, 46, 1108-1115.

Fletcher, J. M., Shaywitz, S. E., Shankweiler, D. P., Katz, L., Liberman, I. Y., Stuebing, K. K., Francis, D. J., Fowler, A. E., \& Shaywitz, B. A. (1994). Cognitive profiles of reading disability: Comparisons of discrepancy and low achievement definitions. Journal of Educational Psychology, 86, 6-23.

Fraser, J., Goswami, U., \& Conti-Ramsden, G. (2010). Dyslexia and specific language impairment: The role of phonology and auditory processing. Scientific Studies of Reading, 14, 8-29.

Gray, S. (2004). Word learning by preschoolers with specific language impairment: Effect of phonological or semantic cues. Journal of Speech, Language, and Hearing Research, 48, 1452-1467.

Hammill, D. D., \& Bartel, N. R. (1990). Teaching students with learning and behavior problems (5th ed.). Boston, MA: Allyn \& Bacon.

Larkin, R. F., \& Snowling, M. J. (2008). Comparing phonological skills and spelling abilities in children with reading and language impairments. International Journal of Communication Disorders, 43, 111-124.

Larsen, S. C., \& Hammill, D. D. (1994). Test of written spelling (3rd ed.). Austin, TX: Pro-Ed.

Leonard, L. B. (1998). Children with specific language impairment. Cambridge, MA: MIT Press.

Lyon, G. R., Shaywitz, S. E., \& Shaywitz, B. A. (2003). A definition of dyslexia. Annals of Dyslexia, 53, 1-14.

Mackie, C., \& Dockrell, J. E. (2004). The nature of written language deficits in children with SLI. Journal of Speech, Language, and Hearing Research, 47, 1469-1483.

Magnusson, E., \& Naucler, K. (1990). Reading and spelling in language-disordered children-linguistic and metalinguistic prerequisites: Report on a longitudinal study. Clinical Linguistics $\mathcal{E}$ Phonetics, 4, 49-61.

Masterson, J., \& Apel, K. (2010). The spelling sensitivity score: Nothing developmental changes in spelling knowledge. Assessment for Effective Intervention, 36, 35-45.

McArthur, G. M., Hogben, J. H., Edwards, V. T., Heath, S. M., \& Mengler, E. D. (2000). On the "specifics" of specific reading disability and specific language impairment. Journal of Child Psychology and Psychiatry and Allied Disciplines, 41, 869-874.

Meyer, M. S., Wood, F. B., Hart, L. A., \& Felton, R. H. (1998). Selective predictive value of rapid automatized naming in poor readers. Journal of Learning Disabilities, 31, 106-117.

Moats, L. C. (1983). A comparison of the spelling errors of older dyslexic and second-grade normal children. Annals of Dyslexia, 33, 121-140.

Nation, K., \& Snowling, M. J. (1998a). Semantic processing and the development of word-recognition skills: Evidence from children with reading comprehension difficulties. Journal of Memory and Language, 39, 85-101.

Nation, K., \& Snowling, M. J. (1998b). Individual differences in contextual facilitation: Evidence from dyslexia and poor reading comprehension. Child Development, 69, 996-1011.

Naucler, K. (2004). Spelling development in Swedish children with and without language impairment. Journal of Multilingual Communication disorders, 2, 207-215.

Newcomer, P., \& Hammill, D. (1988). Test of language development-primary (2nd ed.). Austin, TX: Pro-Ed.

Pennington, B. F., Gilger, J. W., Olson, R. K., \& DeFries, J. C. (1992). The external validity of age- verse IQ-discrepancy definitions of a reading disability: Lessons from a twin study. Journal of Learning Disabilities, 25, 562-573.

Plaut, D. C., McClelland, J. L., Seidenberg, M. S., \& Patterson, K. (1996). Understanding normal and impaired word reading: Computational principles in quasi-regular domains. Psychological Review, 103, 56-115.

Puranik, C. S., Lombardino, L. J., \& Altmann, L. J. (2007). Writing through retellings: An exploratory study of language-impaired and dyslexic populations. Reading and Writing, 20, 251-272.

Rice, M. L., \& Wexler, K. (1996). Toward tense as a clinical marker of specific language impairment in Englishspeaking children. Journal of Speech and Hearing Research, 39, 1239-1257.

Ricketts, J., Bishop, D. V. M., \& Nation, K. (2008). Investigating orthographic and semantic aspects of word learning in poor comprehenders. Journal of Research in Reading, 31, 117-135.

Seidenberg, M. S., \& McClelland, J. L. (1989). A distributed, developmental model of word recognition and naming. Psychological Review, 96, 523-568. 
Semel, E., Wiig, E., \& Secord, W. (1995). Clinical evaluation of language fundamentals (3rd ed.). San Antonio, TX: Psychological Corporation.

Shaywitz, S. E., Shaywitz, B. A., Fletcher, J. M., \& Escobar, M. D. (1990). Prevalence of reading disability in boys and girls: Results of the Connecticut longitudinal study. Journal of the American Medical Association, 264, 998-1002.

Snowling, M. J., Bishop, D. V. M., \& Stothard, S. E. (2000). Is preschool language impairment a risk factor for dyslexia in adolescence? Journal of Child Psychology and Psychiatry and Allied Disciplines, 41, 587-600.

Snowling, M. J., Gallagher, A., \& Frith, U. (2003). Family risk of dyslexia is continuous: Individual differences in the precursors of reading skill. Child Development, 74, 358-373.

Strain, E., Patterson, K., \& Seidenberg, M. S. (1995). Semantic effects in single-word naming. Journal of Experimental Psychology, 21, 1140-1154.

Swanson, H. L., Trainin, G., Necoechea, D. M., \& Hammill, D. D. (2003). Rapid naming, phonological awareness, and reading: A meta-analysis of the correlation evidence. Review of Educational Research, 73, 407-440.

Tomblin, J. B., Records, N., Buckwalter, P., Zhang, X., Smith, E., \& O'Brien, M. (1997). Prevalence of specific language impairment in kindergarten children. Journal of Speech, Language, and Hearing Research, 40, 1245-1260.

Tomblin, J. B., Records, N., \& Zhang, X. (1996). A system for the diagnosis of specific language impairment in kindergarten children. Journal of Speech and Hearing Research, 40, 1284-1294.

Tukey, J. W. (1953). The problem of multiple comparisons (Unpublished report). Princeton University, Princeton, NJ.

Vellutino, F. R., Fletcher, J. M., Snowling, M. J., \& Scanlon, D. M. (2004). Specific reading disability (dyslexia): What have we learned in the past four decades? Journal of Child Psychology and Psychiatry, 45, 2-40.

Wallace, G., \& Hammill, D. D. (1994). Comprehensive receptive and expressive vocabulary test. Austin, TX: Pro-Ed.

Wechsler, D. (1991). Wechsler intelligence scale for children - III. San Antonio, TX: The Psychological Corporation.

Wolter, J. A., \& Apel, K. (2010). Initial acquisition of mental graphemic representations in children with language impairment. Journal of Speech, Language, and Hearing Research, 53, 179-195.

Woodcock, R. (1987). Woodcock reading mastery tests - revised. Circle Pines, MN: American Guidance Services.

Zourou, F., Ecalle, J., Magnan, A., \& Sanchez, M. (2010). The fragile nature of phonological awareness in children with specific language impairments: Evidence from literacy development. Child, Language, Teaching, and Therapy, 26, 347-358.

Zutell, J., \& Rasinski, T. (1989). Reading and spelling connections in third and fifth grade students. Reading Psychology, 10, 137-155. 